Lepr Rev (1989) 60, 8-19

\title{
Evaluation of Mycobacterium leprae antigens in the serological monitoring of a clofazimine-based chemotherapeutic study of dapsone resistant lepromatous leprosy patients in Cebu, Philippines
}

\author{
J T DOUGLAS, * D S HIRSCH, ${ }^{*} \mathrm{~T}$ T FAJARDO, $\dagger$ \\ $\mathrm{R}$ V CELLONA, $\dagger \mathrm{R}$ M ABALOS, $\dagger$ E C DE LA \\ CRUZ, $\dagger$ M G MADARANG, $\uparrow$ M Y L DE WIT $\&$ \\ P R KLATSER $\ddagger$ \\ *University of Hawaii, Department of Microbiology, Honolulu, \\ Hawaii 96822 USA; †Leonard Wood Memorial Center for Leprosy \\ Research, P.O. Box 727, Cebu City, Philippines; $\ddagger$ Royal Tropical \\ Institute, N.H. Swellengrebel Laboratory of Tropical Hygiene, \\ 1105-AZ Amsterdam, The Netherlands.
}

\section{Accepted for publication 12 October 1988}

\begin{abstract}
Summary Thirty-one dapsone resistant lepromatous leprosy patients receiving clofazimine based therapy were serologically monitored throughout their 5-year period of treatment. Sequentially collected sera were used to examine 4 Mycobacterium leprae antigens to evaluate their usefulness in ELISA's for monitoring the progress of their therapy. The ELISA results were compared with decline in bacterial load over the treatment period and with duration of treatment. In addition the ELISA's were compared with each other. The ELISA's based on the measurement of IgM antibodies to the two neoglycoproteins (NDO and NTO) representing the phenolic glycolipid antigen of $M$. leprae were found to be the most effective with regard to monitoring treatment. A whole $M$. leprae based ELISA was less efficient in monitoring treatment because it failed to measure antibodies in 5 out of 31 patients. The ELISA-inhibition test based on the detection of antibodies to a species-specific epitope on the $36 \mathrm{~K}$ antigen of $M$. leprae was less suitable because of persistent reactivity during therapy.
\end{abstract}

\section{Introduction}

The emergence of dapsone resistant Mycobacterium leprae has become an increasing concern in recent years. ${ }^{1}$ As a result the World Health Organization has developed a multidrug therapy (MDT)

$\S$ Deceased 8 January 1988. 
protocol using a 3-drug regimen for lepromatous leprosy patients. ${ }^{1}$ A difficulty in treating these patients is in monitoring the effectiveness of therapy. Currently, eff ective treatment is monitored by clinical evaluation and bacterial index. Both of these methods are liable to subjective interpetation. Serological monitoring could provide a needed additional quantitative test.

One of the components of MDT is clofazimine. Recently, at the Leonard Wood Memorial Research Center, Cebu, Philippines, we were given the opportunity to test sequentially collected sera from 31 patients harbouring dapsone resistant $M$. leprae. These patients received a clofaziminebased therapy regimen for a period of 5 years. The sera were collected sequentially over a 5 -year period, permitting the monitoring of individual patients over the course of therapy.

In this article we describe the results of 4 serological tests measuring antibody reactivity to different $M$. leprae antigens throughout the course of a clof azimine-based treatment. Three tests measured IgM antibodies, 2 to neoglycoprotein antigens representing the phenolic glycolipid I of $M$. leprae, one of which was a disaccharide antigen (NDO-ELISA) and the other was a trisaccharide antigen (NTO-ELISA) ${ }^{2-6}$. A third antigen tested was whole irradiated $M$. leprae (MLEP-ELISA). ${ }^{7}$ The fourth test (ELISA-INH) was based on the inhibition of monoclonal antibody binding by human sera to a species-specific epitope on the $36 \mathrm{~K}$ protein antigen of $M$. leprae. . $^{8-10}$

The test results were correlated with duration of treatment and bacterial index (BI). Furthermore the usefulness of the antigens represented by the 4 tests were analysed in relation to each other and in monitoring the clofazimine-based therapy of these lepromatous leprosy patients.

\section{Methods}

\section{CASE DATA}

Sera for this study were collected from patients with dapsone resistant $M$. leprae who participated in the Joint Chemotherapy Trial (JCT) conducted by Leonard Wood Memorial Center for Leprosy Research in Cebu, Philippines in collaboration with the Sasakawa Health Foundation, Tokyo, Japan. Sera of patients from 2 chemotherapeutic protocols ('IIa' and 'IIc') of the Joint Chemotherapy study were used. Regimen 'IIa' received clofazimine, $100 \mathrm{mg}, 3$ times a week for 5 years and rifampicin, $600 \mathrm{mg} /$ day for 4 weeks. Regimen 'IIc' received clof azimine, $100 \mathrm{mg}, 3$ times a week for 5 years and rifampicin, $1 \cdot 2 \mathrm{~g}$ once a month for 24 weeks ( 6 doses). Medication was administered under the supervision of a nurse. The patients were relapsed, previously treated lepromatous, with proven DDS resistant organism (by mouse footpad inoculation as described by Shepard) ${ }_{1}^{11}$ free of any serious intercurrent disease and screened by chest X-ray to be free of tuberculosis on admission to the trial. A total of 32 patients were sequentially admitted and randomly allocated to either regimen 'IIa' or 'IIc'. A total of 16 patients, 13 males, ranging from 19 years to 47 years (average age, $35 \cdot 5$ years), and 3 females, ranging from 36 years to 44 years (average age $40 \cdot 0$ years), were admitted to the therapy group 'IIa'. All were clinically and histologically $\mathrm{LL}^{12}$ with an average bacterial index of $4 \cdot 7 \pm 0 \cdot 7$. A total of 16 patients, 10 males, ranging from 18 years to 57 years (average age, 36.1 years) and 6 females, ranging from 12 years to 48 years (average age, $24 \cdot 2$ years), with an average bacterial index of $4 \cdot 2 \pm 0 \cdot 8$, were admitted to the therapy group 'IIc'. Three patients in group 'IIa' and 4 patients in group 'IIc', absconded during the course of the trial.

Preliminary evaluation did not show any significant differences between the 2 regimens in terms of clinical improvement and reduction in the average bacterial index in the smears. However, some reduction in the occurrence of moderate to severe ENL was noted among patients on "IIc' regimen.

SERA

The sera from each patient were collected on admission and sequentially every 12 months during the 5 -year period of therapy. 


\section{INDIRECT ELISA}

The ELISA used in this report was an indirect assay with a $0.05-\mathrm{ml}$ suspension of antigen dried onto ' $U$ ' bottom microtitre plates. Antigen coated wells were blocked to prevent nonspecific binding by adding $0.075 \mathrm{ml}$ of $5.0 \%$ goat serum or $5.0 \%$ BSA (bovine serum albumin) in phosphate buffered saline, $\mathrm{pH} 7 \cdot 2$ (PBS) and incubating overnight at $4^{\circ} \mathrm{C}$ or for $2 \mathrm{~h}$ at $37^{\circ} \mathrm{C}$. Serum was diluted 1:500. An antihuman IgM conjugate was used with these antigens. None of the sera were found to exhibit non-specific binding to uncoated and BSA-coated plates. Positive and negative control sera were used on each plate to adjust for plate-to-plate and day-to-day variation. The remainder of the assay was carried out as previously described. ${ }^{13-15}$

\section{INDIRECT ELISA ANTIGENS}

Three antigens were tested: whole armadillo derived irradiated $M$. leprae and 2 neoglycoprotein antigens one of which mimics the 2 terminal sugars and the other mimicking the 3 terminal sugars of the phenolic glycolipid I (PG-1) of M. leprae. ${ }^{6}$ These semi-synthetic antigens are: ND-O-BSA (natural disaccharide) with octyl linkage to bovine serum albumin; and NT-O-BSA (natural trisaccharide) with an octyl linker arm attached to BSA. ${ }^{16}$ The octyl-linked neoglycoprotein antigens, ND-O-BSA and NT-O-BSA, and whole $M$. leprae were provided under NIH contract (NO1 AI-52582) by Dr P. Brennan, Colorado State University. The ELISA in which ND-O-BSA was used as antigen is ref erred to as NDO-ELISA, the ELISA with NT-O-BSA as NTO-ELISA and the ELISA with $M$. leprae as MLEP-ELISA.

\section{INDIRECT ELISA ANTIGEN PREPARATION}

Immulon II plates (Dynatech Laboratories, Alexandria, VA, 22314) were coated with antigen in a volatile buffer. The whole cells, $M$. leprae used as ELISA antigen, were suspended in a volatile coating buffer at a concentration of 0.04 absorbance units at $420 \mathrm{mn}$. The volatile coating buffer used was $0.01 \mathrm{M}$, ammonium acetate/carbonate, $\mathrm{pH} 8.2$. The ND-O-BSA and NT-O-BSA were diluted from a concentrated solution of $100 \mu \mathrm{g} / \mathrm{ml}$ to $0.3 \mu \mathrm{g} / \mathrm{ml}$ and mixed thoroughly. Each of the 3 antigens was coated on microtitre plates by adding $0.05 \mathrm{ml}$ of antigen suspension to each well. The plates were then incubated overnight at $37^{\circ} \mathrm{C}$ to dry the antigen onto the plate. Each well was examined for uniform coating and any unevenly coated wells were eliminated from use. The antigen coated plates could then be stored for several months at room temperature. ${ }^{13}$

\section{ELISA INHIBITION TEST}

Polystyrene ELISA microtitre plates (Dynatech, Alexandria, VA, USA) were coated with $100 \mu \mathrm{l}$ per well of a soluble $M$. leprae preparation $(0.5 \mu \mathrm{g} / \mathrm{ml})$ in $0.05 \mathrm{M}$ sodium bicarbonate buffer, $\mathrm{pH} 9 \cdot 6$, for $18 \mathrm{~h}$ at $37^{\circ} \mathrm{C}$. The plates were washed 3 times with phosphate buffered saline (PBS), containing $0.05 \%$ Tween 20 . Simultaneously to each well was added $20 \mu \mathrm{l}$ of serum and $80 \mu \mathrm{l}$ of peroxidaselabelled monoclonal antibody F47- $9^{9}$ diluted $1: 1000$ in PBS containing $0 \cdot 1 \%$ Tween 20 and $0 \cdot 6 \%$ $\mathrm{BSA}$ and the plates were incubated for $3 \mathrm{~h}$ at $37^{\circ} \mathrm{C}$. Sera were tested in duplicate. After washing with PBS containing $0 \cdot 05 \%$ Tween 20, wells were incubated with $100 \mu$ l TMB-substrate solution $(12 \mathrm{mg}$ of $3,3^{\prime}, 5 \cdot 5^{\prime}$-tetramethylbenzidine (TMB) in $5 \mathrm{ml}$ of ethanol was added to $15 \mathrm{ml}$ of $0 \cdot 1 \mathrm{M}$ citrate/ phosphate buffer, pH 5.0; $\mathrm{H}_{2} \mathrm{O}_{2}$ was added to a final concentration of $0 \cdot 015 \%$ ). Reactions were stopped after $15 \mathrm{~min}$ by the addition of $50 \mu \mathrm{l} 2 \mathrm{M} \mathrm{H}_{2} \mathrm{SO}_{4}$. Resulting absorbances were measured at $450 \mathrm{~nm}$. Each test plate contained negative $(\mathrm{OD}=1 \cdot 5)$ and positive control sera on each plate to adjust for plate-to-plate and day-to-day variation. The percentage inhibition of the sera was calculated as $[(1-\mathrm{OD} / \mathrm{OD}$ neg $) \times 100 \%] .{ }^{9}$ The ELISA-inhibition test is referred to as ELISA-INH. 


\section{STATISTICAL ANALYSIS}

As previously stated, preliminary evaluation did not detect significant differences in the 2 treatment regimens according to clinical improvement and reduction in average BIs; however, some reduction in the occurrence of moderate to severe ENL was noted in patients of the IIc regimen. Statistical analyses of MLEP-ELISA, NDO-ELISA, NTO-ELISA, INH-ELISA and BI values were not significantly different between the 2 treatment regimens. Because of these similarities between the 2 treatment groups, data were combined for analysis of test values and how these values changed over the duration of treatment.

Because of the long follow-up period all sera samples could not be obtained for all patients. Sera were collected on only 9 out of 31 cases for all collection periods; most had 1 serum sample missing at one of the collection periods. Consequently, matched analysis over the entire 5-year period was not possible for all 31 cases.

After preliminary evaluation of the data, it was apparent that the greatest declines in test values were during the first 3 years of treatment. For this period of treatment there were 17 cases for which sera were collected at all sample times, from 0 to 36 months of treatment, thus allowing for matched analysis of each of these cases throughout the first 3 years of treatment.

Whenever ELISA or BI values were compared for a time or between each other within a given time period, homogeneity of variance was first evaluated. If homogeneity of variance was fulfilled, then parametric matched analyses were performed, e.g. repeated measures analysis of variance (ANOVA) and paired $t$ test. If homogeneity of variance was in question or if the data was in a form for which a nonparametric analysis was better, then a Kruskal-Wallis ANOVA ${ }^{17}$ was used when comparing 3 or more variables and a Wilcoxon sign rank analysis ${ }^{18}$ for paired values. Since median values for BIs are better central values at any given sample time, BI values also were evaluated by median analyses.

Both Pearson and Spearman correlation coefficients ${ }^{19,20}$ were calculated between ELISA results and in combination with BI or INH results. Coefficients of determination (i.e. $\mathrm{r}^{2}$ ) were calculated from linear regression analysis as: (regression sum of squares/total sum of squares) $\times 100 \%$. These values were calculated to provide an indication of the amount of the total variation which could be explained by the regression of the two variables under consideration.

All probabilities presented in the results are two-tailed values.

To provide an overallevaluation of how the indirect ELISAs, the INH-ELISA and BIs changed over time, another set of calculations were prepared. Each initial value for an individual was scored as $100 \%$. For subsequent samples test results were calculated as a percentage of the individual's original test value. These percentage values were then analysed independently by either a parametric or nonparametric ANOVA.

\section{Results}

ELISA AND BI VALUES DURING THERAPY

Overall mean ELISA and BI values for the 31 cases and the standard deviations at 1-year intervals during the course of treatment are presented in Table 1. Five patients who gave negative values in the MLEP-ELISA throughout the study period had high OD values in the NDO- and NTOELISA's. Four of these 5 patients had high inhibition values in ELISA-1NH. Sera from 3 patients which gave negative inhibition values throughout the study period had high OD values in the other 3 ELISA tests. One patient was negative in all 4 tests throughout the study period.

Since the greatest declines were observed during the first 3 years of treatment, all cases during this period from whom sera were collected at every sampling period were selected to allow for matched analysis of test values over time. Means and standard deviations for this group are 
Table 1. Overall mean ELISA and BI values by treatment duration

\begin{tabular}{|c|c|c|c|c|c|c|}
\hline \multirow[b]{2}{*}{ Test } & \multicolumn{6}{|c|}{ Therapy/months } \\
\hline & 0 & 12 & 24 & 36 & 48 & 60 \\
\hline NDO-ELISA & $\begin{array}{c}1.13^{*} \\
\pm 0.87 \\
(31)\end{array}$ & $\begin{array}{r}0.67 \\
\pm 0 \cdot 81 \\
(26)\end{array}$ & $\begin{array}{r}0.43 \\
+0.64 \\
(26)\end{array}$ & $\begin{array}{c}0.4 \\
+0.64 \\
(28)\end{array}$ & $\begin{array}{r}0.38 \\
\pm 0.61 \\
(24)\end{array}$ & $\begin{array}{r}0.37 \\
+0.55 \\
(19)\end{array}$ \\
\hline NTO-ELISA & $\begin{array}{c}1 \cdot 08 \\
\pm 0 \cdot 76 \\
(31)\end{array}$ & $\begin{array}{c}0 \cdot 67 \\
\pm 0 \cdot 8 \\
(26)\end{array}$ & $\begin{array}{r}0.47 \\
+0.66 \\
(26)\end{array}$ & $\begin{array}{c}0.46 \\
\pm 0.69 \\
(23)\end{array}$ & $\begin{array}{r}0.32 \\
+0.46 \\
(15)\end{array}$ & $\begin{array}{r}0.29 \\
+0.31 \\
(7)\end{array}$ \\
\hline MLEP-ELISA & $\begin{array}{c}0.73 \\
\pm 0 \cdot 7 \\
(31)\end{array}$ & $\begin{array}{r}0.42 \\
\pm 0 \cdot 51 \\
(26)\end{array}$ & $\begin{array}{c}0.3 \\
+0.38 \\
(26)\end{array}$ & $\begin{array}{r}0 \cdot 15 \\
\pm 0 \cdot 15 \\
(23)\end{array}$ & $\begin{array}{c}0 \cdot 12 \\
\pm 0 \cdot 12 \\
(15)\end{array}$ & $\begin{array}{r}0.08 \\
+0.05 \\
(7)\end{array}$ \\
\hline INH-ELISA & $\begin{array}{r}43 \cdot 27 \\
+29 \cdot 31 \\
(31)\end{array}$ & $\begin{array}{r}26.86 \\
\pm 27 \cdot 59 \\
(26)\end{array}$ & $\begin{array}{r}26.09 \\
+26.53 \\
(26)\end{array}$ & $\begin{array}{r}20.62 \\
+23.89 \\
(28)\end{array}$ & $\begin{array}{c}19 \cdot 7 \\
+25 \cdot 84 \\
(24)\end{array}$ & $\begin{array}{r}23.97 \\
+23.7 \\
(19)\end{array}$ \\
\hline $\mathrm{BI}$ & $\begin{array}{r}4 \cdot 42 \\
+0 \cdot 85 \\
(31)\end{array}$ & $\begin{array}{c}3 \cdot 00 \\
+1 \cdot 1 \\
(26)\end{array}$ & $\begin{array}{r}1.35 \\
+0.94 \\
(26)\end{array}$ & $\begin{array}{c}0.81 \\
\pm 0.79 \\
(27)\end{array}$ & $\begin{array}{r}0.35 \\
+0.71 \\
(23)\end{array}$ & $\begin{array}{r}0.11 \\
+0.47 \\
(18)\end{array}$ \\
\hline
\end{tabular}

* Results are expressed as the mean value \pm standard deviation. The number of samples tested is given in parentheses.

Table 2. Mean ELISA and BI values of cases matched over treatment duration

\begin{tabular}{|c|c|c|c|c|}
\hline \multirow[b]{2}{*}{ Test } & \multicolumn{4}{|c|}{ Therapy (months) } \\
\hline & 0 & 12 & 24 & 36 \\
\hline NDO-ELISA & $1 \cdot 02 \pm 0.96^{*}$ & $0.64 \pm 0.81$ & $0.49 \pm 0.77$ & $0.43 \pm 0.8$ \\
\hline NTO-ELISA & $0.97 \pm 0.77$ & $0.64 \pm 0.85$ & $0.52 \pm 0.79$ & $0.45 \pm 0.78$ \\
\hline MLEP-ELISA & $0.78 \pm 0.73$ & $0.36 \pm 0.39$ & $0 \cdot 28 \pm 0.44$ & $0 \cdot 17 \pm 0 \cdot 17$ \\
\hline $\begin{array}{l}\text { INH-ELISA } \\
\text { BI: }\end{array}$ & $36 \cdot 32 \pm 32 \cdot 06$ & $25 \cdot 61 \pm 28 \cdot 32$ & $19 \cdot 95 \pm 26 \cdot 22$ & $19 \cdot 81 \pm 26 \cdot 5$ \\
\hline $\begin{array}{l}\text { Mean } \pm s \\
\text { Median }\end{array}$ & $4 \cdot 53 \pm \frac{ \pm}{5} 0 \cdot 72$ & $3 \cdot 06 \pm \frac{1}{3} \cdot 14$ & $1 \cdot 35 \pm \frac{0}{1} 0 \cdot 86$ & $0 \cdot 82 \pm 0.73$ \\
\hline
\end{tabular}

presented in Table 2. Year-to-year decreases for each of these 17 cases could then be averaged according to mean declines in OD values for indirect ELISA values (Table 3) and mean declines in percent inhibition or BI values (Table 4).

As presented in Table 3, from 0 to 12 months of treatment, the average decline in OD values for NDO-ELISA was 0.384 units ( $p 0.001)$, for NTO-ELISA was 0.328 units $(p 0.01)$, and for MLEPELISA was 0.424 units $(p 0.01)$. For the next year (12-24 months of treatment), the average decline for NDO-ELISA was another 0.153 units $(p 0.001)$ and for NTO-ELISA another $0 \cdot 125$ units ( $p$ 0.001); the average decline of 0.076 units for MLEP-ELISA was not significant. Af ter 24 months of treatment, the year-to-year declines in any of the OD values were not significant.

Table 4 illustrates that for INH-ELISA the average year-to-year decline in percent inhibition for 
Table 3. Average decreases of paired OD values by antigen and by duration of treatment

\begin{tabular}{lccc}
\hline & \multicolumn{2}{l}{ ELISA OD value decreases by antigen } \\
\cline { 2 - 4 } $\begin{array}{l}\text { Treatment period } \\
\text { (months) }\end{array}$ & NDO & NTO & MLEP \\
\hline $0-12$ & $-0.384 \ddagger$ & $-0.328 \dagger$ & $-0.424 \dagger$ \\
$12-24$ & $-0.153 \ddagger$ & $-0.125 \ddagger$ & -0.076 \\
$24-36$ & -0.064 & -0.064 & -0.112 \\
\hline
\end{tabular}

$n=17$ (persons for which all measurements were taken for each of the above four sampling periods, i.e. $0,12,24$ and 36 months of treatment).

${ }^{*} p<0.05 ; \dagger p<0.01 ; \ddagger p<0.001$; All others: no significant decrease in OD value.

Table 4. Decreases in INH-ELISA values and BI values by treatment duration

\begin{tabular}{lcc} 
Treatment period & INH-ELISA $(\%$ inhibition $) \S$ & BI $\dagger \dagger$ \\
\hline (months) & & \\
$0-12$ & $10 \cdot 71^{*}$ & $-1 \cdot 47 \ddagger$ \\
$12-24$ & $-5 \cdot 66^{*}$ & $-1 \cdot 71 \ddagger$ \\
$24-36$ & $-0 \cdot 14$ & $-0.53^{*}$ \\
\hline
\end{tabular}

$$
n=17
$$

* $p<0.05 ; \dagger p<0.01 ; \ddagger p<0.001$.

$\S$ Average decreases were calculated from paired $t$ test analysis; $p$ values were similar whether calculated from both paired $t$ test or Wilcoxon sign rank analyses.

$\dagger \dagger$ Average decreases in BI values were calculated using paired $t$ analysis; $p$ values represent both paired $t$ results and Wilcoxon sign rank analysis. Results from median analysis similarly agree.

Table 5. Frequency of cases by BI and by treatment duration

\begin{tabular}{|c|c|c|c|c|c|c|c|}
\hline \multirow{2}{*}{$\begin{array}{l}\text { Treatment } \\
\text { duration } \\
\text { (months) }\end{array}$} & \multicolumn{7}{|c|}{ BI values } \\
\hline & 6 & 5 & 4 & 3 & 2 & 1 & 0 \\
\hline $0(n=31)$ & 1 & 16 & 10 & 3 & 1 & & \\
\hline $12(n=26)$ & & $-\overline{1}$ & 8 & 11 & 2 & 4 & \\
\hline $24(n=26)$ & & & & $-\overline{2}$ & 11 & 7 & 6 \\
\hline $36(n=27)$ & & & & & 6 & 10 & 11 \\
\hline $48(n=23)$ & & & & 1 & & $-\overline{5}$ & 17 \\
\hline $60(n=18)$ & & & & & 1 & & 17 \\
\hline
\end{tabular}

For each treatment duration category one of the cells has been underscored. This cell represents the location of the median value for that category. 
0-12 months of treatment was $10 \cdot 71(p 0 \cdot 05)$, for 12-24 months of treatment was another $5.66(p$ $0 \cdot 05$ ), and further declines after 24 months were not significant. BI values presented are average year-to-year declines of 1.47 BI during 0-12 months of treatment, another 1.71 BI during 12-24 months of treatment ( $p 0.001)$, and another $0.53 \mathrm{BI}$ during $24-36$ months of treatment $(p 0.05)$. After 36 months of treatment year-to-year BI declines were no longer significant. Since BI values are actually ranks, median values also were analysed in year-to-year declines. The results of median analyses similarly compare to the parametric analyses presented in Table 4 . Refer also to Table 5 for a frequency distribution of cases, by BI values, at each treatment duration sampling period.

\section{CORRELATIONS BETWEEN TESTS AND BI}

For any given treatment duration sample, both Pearson and Spearman correlation coefficients were calculated for indirect ELISA values, INH-ELISA values and BI values. Spearman probabilities were similar to Pearson values so Pearson values were used, allowing calculation of $r^{2}$ from linear regression analysis. These correlations are presented in Table 6 . The OD values of the indirect ELISA's or INH-ELISA were not significantly correlated with BI values.

NDO-, NTO- and MLEP-ELISA values were significantly correlated with each other. NDOELISA and NTO-ELISA correlations were excellent, ranging from 0.963 to $0.998(p 0.001)$ with coefficients of determination (i.e. $r 2$ ) ranging from about $92 \cdot 7 \%$ to about $99 \cdot 6 \%$, respectively. MLEP-ELISA values were significantly correlated with either NDO-ELISA or NTO-ELISA, with correlations ranging from $0.631(p 0.01)$ to $0.887(p 0.001)$. These latter correlations, however, translate to $r^{2}$ values of $39.8 \%$ to $78.7 \%$, respectively. This indicates that the agreement between

Table 6. Correlation coefficients by test and treatment duration

\begin{tabular}{|c|c|c|c|c|c|}
\hline Months & NDO & NTO & MLP & INH & BI \\
\hline \multicolumn{6}{|l|}{ NDO: } \\
\hline 0 & - & $0.963 \ddagger$ & $0.631 \dagger$ & $0.593^{*}$ & -0.192 \\
\hline 12 & - & $0.993 \ddagger$ & $0 \cdot 887 \ddagger$ & 0.421 & $0 \cdot 109$ \\
\hline 24 & - & $0.997 \ddagger$ & $0.878 \ddagger$ & 0.438 & 0.06 \\
\hline 36 & - & $0.998 \ddagger$ & $0.795 \ddagger$ & $0 \cdot 339$ & $0 \cdot 126$ \\
\hline \multicolumn{6}{|l|}{ NTO: } \\
\hline 0 & & - & $0.701 \uparrow$ & $0.569^{*}$ & $-0 \cdot 163$ \\
\hline 12 & & - & $0.881 \ddagger$ & $0 \cdot 392$ & $0 \cdot 104$ \\
\hline 24 & & - & $0.855 \ddagger$ & $0 \cdot 397$ & 0.033 \\
\hline 36 & & - & $0.789 \ddagger$ & $0 \cdot 325$ & $0 \cdot 11$ \\
\hline \multicolumn{6}{|l|}{ MLP: } \\
\hline 0 & & & - & $0 \cdot 396$ & -0.044 \\
\hline 12 & & & - & $0.551^{*}$ & 0.357 \\
\hline 24 & & & - & $0.654 \dagger$ & $0 \cdot 126$ \\
\hline 36 & & & - & $0.646 \dagger$ & $0 \cdot 309$ \\
\hline \multicolumn{6}{|l|}{ INH: } \\
\hline 0 & & & & - & -0.379 \\
\hline 12 & & & & - & 0.147 \\
\hline 24 & & & & - & -0.035 \\
\hline 36 & & & & - & 0.082 \\
\hline BI: & & & & & - \\
\hline
\end{tabular}

All probabilities are based on $15 \mathrm{df} p<0.001$. ${ }^{*} p<0.05 ; \dagger p<0.01 ; \ddagger p<0.001$. 
Table 7. Mean paired differences in OD values at given treatment duration periods

\begin{tabular}{|c|c|c|c|c|}
\hline & \multirow{2}{*}{$\begin{array}{c}\text { Treatment } \\
\text { Duration (months) }\end{array}$} & \multicolumn{3}{|c|}{ Antigen } \\
\hline & & NDO & NTO & MLEP \\
\hline \multirow[t]{4}{*}{ NDO: } & $0(30 \mathrm{df})$ & - & 0.045 & $0.391 \dagger$ \\
\hline & $12(25 \mathrm{df})$ & - & 0.002 & $0 \cdot 246^{*}$ \\
\hline & $24(25 \mathrm{df})$ & - & -0.041 & $0 \cdot 132$ \\
\hline & 36 (16df) & - & -0.028 & $0 \cdot 256$ \\
\hline \multirow[t]{4}{*}{ NTO: } & $0(30 \mathrm{df})$ & & & $0.346 \dagger$ \\
\hline & $12(25 \mathrm{df})$ & & - & $0 \cdot 244^{*}$ \\
\hline & $24(25 \mathrm{df})$ & & - & $0.173^{*}$ \\
\hline & 36 (16df) & & - & $0 \cdot 284$ \\
\hline MLP & & & & - \\
\hline
\end{tabular}

MLEP-ELISA with either NDO-ELISA or NTO-ELISA is not as high as the agreement between NDO-ELISA and NTO-ELISA.

At the initial sample (i.e. 0 months of treatment) NDO-ELISA and NTO-ELISA were significantly correlated with INH-ELISA $(r=0.593, p 0 \cdot 05 ; r=0.569, p 0.05$, respectively). These translate to $r^{2}$ values of $35.2 \%$ and $32 \cdot 4 \%$, respectively. At subsequent sample periods INH-ELISA was not significantly correlated with either NDO-ELISA or NTO-ELISA.

MLEP-ELISA was significantly correlated with INH-ELISA at 12, 24 and 36 months of treatment $(r=0.551, p 0.05 ; r=0.654, p 0.01 ; r=0.646, p 0 \cdot 01$, respectively $)$. Coefficients of

Table 8. ELISA and BI percentage units over the course of treatment

\begin{tabular}{lcccccc}
\hline & \multicolumn{5}{c}{ Therapy (months) } \\
\cline { 2 - 7 } Test & 0 & 12 & 24 & 36 & 48 & 60 \\
\hline NDO-ELISA & $100^{*}$ & $52 \cdot 8 \pm 22 \cdot 1 \dagger$ & $35 \cdot 8 \pm 20 \cdot 7$ & $31 \cdot 6 \pm 22 \cdot 2$ & $29 \cdot 8 \pm 18 \cdot 2$ & $28 \cdot 5 \pm 18 \cdot 4$ \\
& $(31)$ & $(26)$ & $(26)$ & $(28)$ & $(24)$ & $(19)$ \\
NTO-ELISA & 100 & $54 \cdot 0 \pm 27 \cdot 2 \dagger$ & $41 \cdot 2 \pm 22 \cdot 2$ & $37 \cdot 6 \pm 24 \cdot 1$ & $29 \cdot 3 \pm 20 \cdot 9$ & NT $\ddagger$ \\
& $(31)$ & $(26)$ & $(26)$ & $(23)$ & $(15)$ & \\
MLEP-ELISA & 100 & $55 \cdot 9 \pm 34 \cdot 9 \dagger$ & $41 \cdot 8 \pm 27 \cdot 9$ & $38 \cdot 3 \pm 35 \cdot 5$ & $27 \cdot 3 \pm 25 \cdot 4$ & NT $\ddagger$ \\
& $(31)$ & $(26)$ & $(26)$ & $(23)$ & $(15)$ & \\
ELISA-INH & 100 & $57 \cdot 2 \pm 45 \cdot 9 \dagger$ & $49 \cdot 2 \pm 32 \cdot 7$ & $40 \cdot 0 \pm 31 \cdot 7$ & $38 \cdot 1 \pm 35 \cdot 4$ & $48 \cdot 8 \pm 33 \cdot 0$ \\
& $(31)$ & $(26)$ & $(26)$ & $(28)$ & $(24)$ & $(19)$ \\
BI & 100 & $69 \cdot 3 \pm 23 \cdot 3 \dagger$ & $29 \cdot 0 \pm 19 \cdot 4$ & $18 \cdot 0 \pm 17 \cdot 2$ & $8 \cdot 0 \pm 16 \cdot 9$ & $2 \cdot 2 \pm 9 \cdot 2$ \\
& $(31)$ & $(26)$ & $(26)$ & $(28)$ & $(24)$ & $(19)$ \\
\hline
\end{tabular}

* The data from each assay were standardized by assigning the initial value at the start of therapy for each patient at $100 \%$. The subsequent values for each patient over the course of treatment was calculated as a percentage of the initial values. Results are expressed as mean value \pm standard deviation thereof. The number of samples tested is given in brackets.

$\dagger$ Mean values throughout the therapy period are significantly lower than the initial values at the start of therapy (Kruskal-Wallis test, $p<0 \cdot 01$ ).

$\ddagger$ Not tested. 


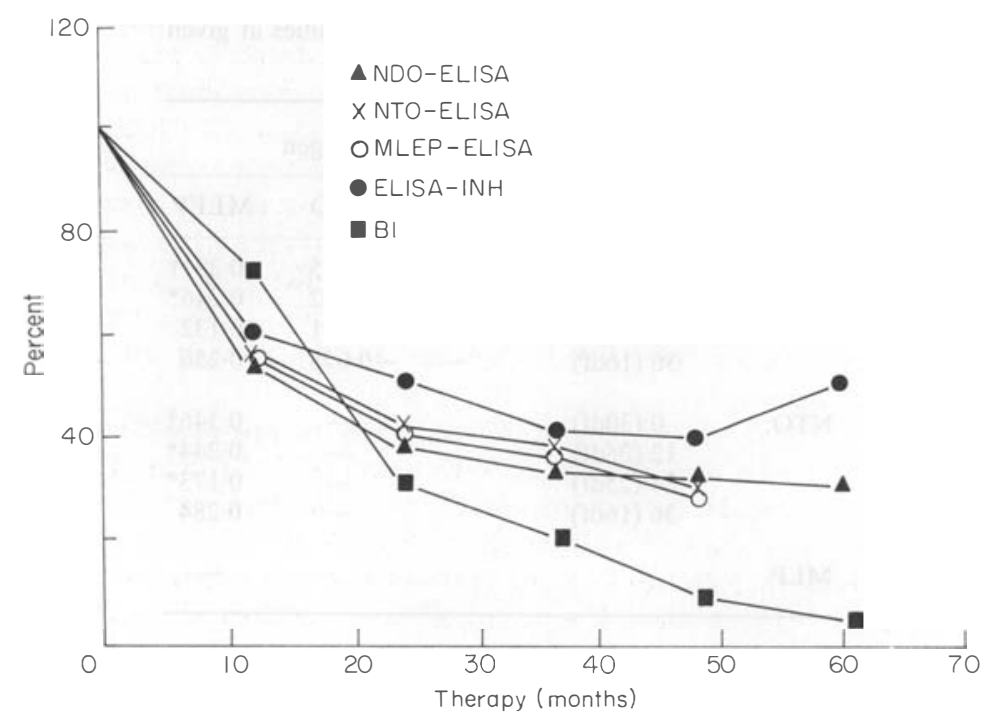

Figure 1. ELISA and BI declines over the course of clofazimine treatment in dapsone resistant lepromatous patients. Graphic representation of the mean values presented in Table 8.

determination were about $30 \cdot 3 \%, 42 \cdot 8 \%$ and $41 \cdot 7 \%$, respectively, thus indicating relatively poor agreement between MLEP-ELISA and INH-ELISA values.

Paired $t$ test analysis was applied to the indirect ELISA values to determine if there were significant differences in OD values depending upon whether NDO, NTO or whole M. leprae (MLEP) were used (Table 7). As presented in Table 7 no significant differences were detected in OD values between NDO-ELISA or NTO-ELISA. Both NDO-ELISA and NTO-ELISA, however, provided consistently higher OD values than did MLEP.

\section{ELISA AND BI VALUES BY PERCENTAGE OF ORIGINAL VALUES}

The data from each assay were standardized by assigning the initial value (i.e. at the start of treatment) for each patient as $100 \%$. The subsequent values for each patient over the course of treatment were calculated as a percentage of the initial values. The averages and standard deviations of these percentages are presented in Table 8 and Figure 1. All 3 indirect ELISAs showed a decline to approximately $30 \%$ of the initial values after $4-5$ years of therapy. The INH-ELISA showed a much slower decline to $40-50 \%$ of the initial values after 4-5 years of therapy. The BI values showed a sharp decline to $30 \%$ of starting values after 2 years of therapy.

\section{Discussion}

Our results indicate a marked decline in ELISA reactivity over the duration of clof azimine-based treatment which parallel the decline in BI. All patients were proven dapsone resistant lepromatous cases by mouse footpad inoculations ${ }^{11}$ and received 2 different chemotherapeutic protocols, which differed only in the duration of rifampicin administration at the beginning of the therapy period (JCTII-A for 4 weeks and JCTII-C for 24 weeks); thereaf ter, clofazimine monotherapy was given for at least $4 \cdot 5$ years until the end of the 5 -year therapy period. Clinical and serological evaluation did not indicate any significant differences between the 2 treatment regimens (JCTII-A and JCTIIC). The data, therefore, were combined from patients of 2 therapy regimens. 
The ELISA's measuring IgM antibodies to the NDO, NTO and whole $M$. leprae antigens showed a significant paired decline in OD values over treatment duration, particularly during the 0 12 month treatment period. During this first year of treatment the average paired declines in OD units for NDO-ELISA was 0.384 units ( $p 0.001)$, for NTO-ELISA was 0.328 units $(p 0.001)$, and for MLEP-ELISA was 0.424 units $(p 0.01)$. The decline in antibody levels to phenolic glycolipid I is not surprising, since the antigen itself, when detected, disappears more rapidly from the circulation as a consequence of effective treatment. ${ }^{29}$ The rapid disappearance of the antigen is most likely due to its low molecular weight and its solubility in body fluids. Using different antigens, ELISA conjugates and therapy protocols, we and others have noted declines of antibody levels during treatment. ${ }^{21-26,31}$ However, here we report the monitoring of dapsone-resistant patients during their secondary course of dapsone-free therapy.

Sequential sera of 5 patients were negative throughout the therapy period using MLEP-ELISA. These patients' sera, however, were positive by NDO- and NTO-ELISAs. The antigens used in these latter ELISAs represent the sugar epitope of the phenolic glycolipid of $M$. leprae, indicating that the MLEP-ELISA does not detect antibody reactivity to this phenolic glycolipid. Given the excellent correlation between NDO-ELISA and NTO-ELISA OD values and the fact that there is no significant difference in these values, it appears that either NDO or NTO can be used and either would provide similar OD results. Although the correlations between NDO-ELISA or NTOELISA with MLEP-ELISA are significant, the $r^{2}$ values are not particularly high. This, combined with the fact that either NDO-ELISA or NTO-ELISA provide significantly higher OD values than MLEP-ELISA and that MLEP-ELISA did not detect 5 cases, indicates that using either NDO or NTO provides better results.

Although all of the indirect ELISA values, the INH-ELISA and the BIs declined significantly over the duration of the treatment period, none of the indirect ELISA values nor the INH-ELISA were significantly correlated with BI values. This, therefore, indicates poor agreement between ELISA values and BI. One explanation could be that whereas BI reflects bacterial load at individual sites, the ELISA could be interpreted as a reflection of systemic bacillary load. Another explanation could be the subjective determination of the BI, such as the selection of sites and interpretation of observations. ${ }^{30}$ This is in contrast to the quantitative, objective findings by ELISA. This suggests that the phenolic glycolipid I based ELISA's using synthetic antigens may be a better method for monitoring patients progress during chemotherapy.

In comparing the correlations between the indirect ELISA's the NDO-ELISA and NTO-ELISA showed excellent correlations (Table 6). This high correlation is not surprising, since the antigens used in these ELISA's mimic phenolic glycolipid I's terminal oligosaccharide, differing only in the third sugar. These results are in agreement with previously published data. ${ }^{6} \mathrm{~A}$ lower correlation was found when these antigens were compared to whole $M$. leprae. This was not unexpected since 5 patients did not show any detectable reactivity in the MLEP-ELISA but did with NDO-ELISA and NTO-ELISA and since MLEP-ELISA consistently provided lower OD values than NDO-ELISA or NTO-ELISA.

Year-to-year paired comparisons of INH-ELISA values showed a significant average decline of 10.71 units $(p 0.05)$ during the first year of treatment and another 5.66 units $(p 0.05)$ during the second year of treatment. Thereafter, the year-to-year declines in INH-ELISA values were not significant. As previously stated, INH-ELISA values were not significantly correlated with BI values. This is in accordance with the finding that 'burned-out' lepromatous and tuberculoid patients frequently have high ELISA-INH values (P. Klatser, unpublished data). Some patients (7 out of 19), however, do decline to negative reactivity, comparable to the values found with uninfected controls and tuberculosis patients. ${ }^{28}$ Similar findings have been reported measuring the persistence of antibodies to the lipoarabinomannan antigen during and up to 10 years of treatment of lepromatous patients. ${ }^{6,27}$ The reasons for and implications of the persistence of antibody production to the $36 \mathrm{~K}$ antigen of $M$. leprae are not clear.

For the monitoring of chemotherapy of lepromatous leprosy patients of the indirect ELISA's 
investigated, NDO-ELISA or NTO-ELISA were found to be the most effective with respect to duration of treatment. It is possible that in some cases the NDO- or NTO-ELISA reactivity may be more accurate reflections of bacterial load. The ELISA-INH is less suitable for monitoring patients on chemotherapy because of persistent reactivity throughout the therapy period. Whether these persistent INH-ELISA reactivities play any role as to relapses requires further investigation.

\section{Acknowledgments}

This research was supported by the Leonard Wood Memorial American Leprosy Foundation, Rockville, Maryland; National Institute of Allergy and Infectious Diseases Grant \#R22 A1 24154; Sasakawa Memorial Health Foundation, Tokyo, Japan; Pacific Health Research Institute, Honolulu, Hawaii and the Netherlands Leprosy Relief Association (NSL), Amsterdam, The Netherlands. We thank the Philippine Government Department of Health for their cooperation. We also thank Ms Manuela Luisa Parrilla, L Mendoza and L Steven for their excellent technical assistance.

\section{References}

1 WHO Study Group. Chemotherapy of leprosy for control programmes. Technical Report Series No. 675, 1982.

${ }^{2}$ Hunter SW, Brennan PJ. A novel phenolic glycolipid from Mycobacterium leprae possibly involved in immunogenicity and pathogenicity. $J$ Bact, 1981; 147: 728-35.

${ }^{3}$ Chatterjee D, Douglas JT, Cho S, Rea TH, Gelber RH, Aspinall GO, Brennan PJ. Synthesis of neoglycoconjugates containing the 3,6-di-O-methyl-B-D-glycopyranosyl epitope and use in serodiagnosis of leprosy. Glycoconjugate J, 1985; 2: 187-208.

${ }^{4}$ Fujiwara T, Hunter SW, Brennan PJ. Chemical synthesis of disaccharides of the specific phenolic glycolipid antigens from Mycobacterium leprae and of related sugars. Carbohydrate Res, 1986; 148: 287-98.

${ }^{5}$ Fujiwara T, Aspinall GO, Hunter SW, Brennan PJ. Chemical synthesis of the trisaccharide unit of the species-specific phenolic glycolipid from Mycobacterium leprae. Carbohydrate Res, 1987; 163: 41-52.

6 Brennan PJ. The carbohydrate containing antigens of M. leprae. Lepr Rev, 1986; 57: Suppl 2, 39-51.

7 Douglas JT, Naka SO, Lee JW. Leprosy ELISA antigen coating buffers and antigens: comparison of $M$. leprae whole cells with other Mycobacteria. Seventeenth Joint Conference On Leprosy Research, USJapan Cooperative Medical Science Program, pp. 316-27, Sendai, August 1982.

8 Klatser PR, van Rens MM, Eggelte TA. Immunochemical characterization of Mycobacterium leprae antigens by the SDS-polyacrylamide gel electrophoresis immunoperoxidase technique (SGIP) using patients' sera. Clin exp Imm, 1984; 56: 537-44.

9 Klatser PR, de Wit MYL, Kolk AHJ. An ELISA-inhibition test for the serology of leprosy. Clin exp Imm, 1985; 62: 468-73.

10 Klatser PR, Hartskeerl RA, van Schooten WCA, Kolk AHJ, van Rens MM, de Wit MYL. Characterization of the 36K antigen of Mycobacterium leprae. Lepr Rev, 1986; 57: Suppl 2, 77-81.

11 Shepard CC. The experimental disease that follows the infection of human leprosy bacilli into footpads of mice. J Exp Med, 1960; 112: 445-54.

12 Ridley DS, Jopling WH. Classification of leprosy according to immunity-a five group system. Int J Lepr, 1965; 34: 255-73.

13 Douglas JT, Naka SO, Lee JW. Development of an ELISA for detection of antibody in leprosy. Int J Lepr, 1984; 52: 19-25.

14 Douglas JT, Murry CJ, Lee JW, Worth RM. Comparison of ELISA antigens for early detection of leprosy. In: Proceedings of the XII International Leprosy Congress: paper 370. 1984.

15 Douglas JT, Steven LM. Comparison of natural and synthetic antigens for the early detection of leprosy. Proceedings 11 th Joint Conference Leprosy and Tuberculosis, US-Japan Cooperative Medical Science Program, p. 143. Tokyo, August 1984.

16 Fujiwara T, Hunter SW, Brennan PJ. Chemical synthesis of disaccharides of the specific phenolic glycolipid antigens from Mycobacterium leprae and of related sugars. Carbohydrate Res, 1986; 148: 287-98.

17 Kruskal WH, Wallis WA. Use of ranks in one-criterion variance of analysis. J Amer Stat Assoc, 1945; 47: 583-621.

18 Wilcoxon F. Individual comparisons by ranking methods. Biometrics Bull, 1945; 1: 80-3. 
19 Pearson ES, Hardley HO. Biometrika Tables for Statisticians. 1966, Vol. 1, 3rd Ed. Cambridge: University Press.

${ }^{20}$ Kendall MG. Rank Correlation Methods. 1948. London: Griffin.

21 Douglas JT, Steven LM, Fa jardo T, Cellona RV, Madarang MG, Abalos RM, Steenbergen GJ. The effects of chemotherapy on antibody levels in lepromatous patients. Lepr Rev, 1988; 59: 127-35.

22 Melsom R, Naafs B, Harboe M, Closs O. Antibody activity against Mycobacterium leprae antigen 7 during the first year of DDS treatment in lepromatous (BL-LL) leprosy. Lepr Rev. 1978; 49: 17-29.

23 Melsom R, Harboe M, Naafs B. Class specific anti-Mycobacterium leprae antibody assay in lepromatous leprosy (BL-LL) patients during the first two to four years of DDS treatment. Int J Le pr, 1982; 50: 271-81.

24 Touw J, Langendijk E, Stoner G, Belechu A. Humoral immunity in leprosy: immunoglobulin G and M antibody responses to Mycobacterium leprae in relation to various disease patterns. Inf Immun, 1982; 36: 885-92.

25 Miller R, Harnisch J, Buchanan T. Antibodies to mycobacterial arabinomannan in leprosy: correlation with reactional states and variation during treatment. Int $J$ Lepr, 1984; 52: 133-9.

${ }^{26}$ Schwerer B, Meeker H, Levis W. IgM antibodies against phenolic glycolipid I from Mycobacterium leprae in leprosy sera: relationship to bacterial index and erythema nodosum leprosum. Acta Lepr 1984; 95: 395402.

27 Hunter SW, Gaylord M, Brennan PJ. Structure and antigenicity of the phosphorylated lipopolysaccaharides antigens from the leprosy and tubercle bacillus. J Biol Chem, 1986; 12345-51.

28 De Wit MYL Klatser PR. Purification and characterization of a 36kDa antigen of M. leprae. J Gen Microbiol 1988; 134: 1541-9.

29 Young DB, Harnish JP, Knight J, Buchanan TM. Detection of phenolic glycolipid I in sera of patients with lepromatous leprosy. J Infect Dis 1985; 152: 1078-81.

30 Georgiev GD, McDougall AC. Skin smears and the bacterial index (BI) in multiple drug therapy leprosy control programs: an unsatisfactory and potentially hazardous state of affairs. Int $J$ Le pr, 1988; 56: 101-4.

${ }^{31}$ Miller RA, Gorder D, Harnisch JP. Antibodies to phenolic glycolipid-I during long-term therapy: serial measurements in individual patients. Int J Le pr, 1987; 55: 633-6. 